\title{
Conselho municipal de educação: análise do princípio da gestão democrática nas legislações do município de São José de Ribamar/MA
}

\author{
Brenda Cristina Ferreira Gomes ${ }^{1}$ \\ Janaina de Araujo Pimenta ${ }^{2}$ \\ Maria José Pires Barros Cardozo ${ }^{3}$
}

\section{Resumo}

O presente artigo tem por objetivo analisar o quadro normativo relativo à gestão democrática da educação. Para tanto, realizou-se pesquisa bibliográfica, a partir da leitura de autores como Bordignon (2009), Cury (2002; 2000) e Peroni (2008), seguida de pesquisa documental com base na análise das legislações do município de São José de Ribamar - MA. Constatou-se que, embora o princípio de gestão democrática seja preconizado como fundamento que sustenta a organização da educação na esfera local, esse tipo de gestão depara-se com dificuldades para ser materializado. O limite que se impõe para a concretização ocorre por meio das normas que não reconhecem os princípios democráticos e não mencionam mecanismos que facilitem ações voltadas para a efetivação da gestão democrática.

Palavras-chave: Gestão Democrática; Conselho Municipal de Educação; Legislação Educacional.

\section{Municipal council of education: analysis of the principle of democratic management in the legislations of the municipality of São José de Ribamar/MA}

\section{Abstract}

This article aims to analyze the normative chart relative to democratic management of education. Therefore, bibliographic research was carried out, based on the reading of authors such as Bordignon (2009), Cury (2002; 2000) and Peroni (2008), and then, documentary research based on the analysis of the laws of the city of São José de Ribamar - MA. It was found that, although the principle of democratic management is recommended as a foundation that supports the organization of education in the local sphere, this type of management faces difficulties to be materialized. The limit that is imposed for the concretization occurs through the norms that do not recognize the democratic principles and do not mention mechanisms that facilitate actions aimed at the effectiveness of democratic management.

Keywords: Democratic Management; Municipal Education Council; Educational Legislation.

\section{Introdução}

O processo de descentralização do poder conferiu aos municípios, por meio da Constituição Federal de 1988 (BRASIL, 2015, Art. 206) e da Lei de Diretrizes e Bases da Educação

\footnotetext{
${ }^{1}$ Universidade Federal do Maranhão (UFMA), São Luís - MA; E-mail: gomesbrenda07@gmail.com.

${ }^{2}$ Universidade Federal do Maranhão (UFMA), São Luís - MA; E-mail: janaina.pimentad@gmail.com

${ }^{3}$ Universidade Federal do Maranhão (UFMA), São Luís - MA; E-mail: maria.cardozo@ufma.br.
} 
de 1996, Lei n.9.394 (BRASIL, 2019, Art.14), a responsabilidade pela gestão da educação com o propósito de aumentar a qualidade dos serviços, proporcionar a participação dos cidadãos e promover melhor gestão dos recursos financeiros de modo que essas unidades territoriais pudessem corresponder às necessidades locais peculiares. Para tanto, o princípio de gestão democrática é estabelecido como fundamento legal que norteará a organização do ensino público nos sistemas de educação. Esse modelo de gestão - visto como um novo modo de administrar - pode ser definido como democrático porque envolve o diálogo entre diferentes interlocutores que almejam a definição das ações de forma coletiva (CURY, 2002). É contrário a qualquer prática paternalista ou autoritária já que se sustenta na liberdade de expressão e na igualdade de participação. Nesse sentido e, de acordo com Cury (2002, p.172), no referido tipo de gestão "os cidadãos querem mais do que serem executores de políticas, querem ser ouvidos e ter presença em arenas públicas de elaboração e nos momentos de tomada de decisão. Tratase de democratizar a própria democracia".

Neste processo atuam os Conselhos de Educação como órgãos colegiados de Estado (BORDIGNON, 2009), que reúnem seus membros para discutirem, elaborarem e tomarem decisões a respeito de políticas educacionais. Têm como uma de suas principais funções a busca pela efetiva aplicação da legislação no âmbito da educação. Desse modo, objetivam garantir o cumprimento das finalidades propostas nas leis, diretrizes, referenciais e parâmetros curriculares para a educação por meio da criação de um espaço de representação social ao estabelecer um elo entre Estado e sociedade civil, elegendo cidadãos da comunidade para participarem como membros desses Conselhos com base no princípio de paridade.

Por ter a função de tornar os aspectos legais mais entendíveis, é possível afirmar que esses órgãos colegiados podem ser vistos como órgãos esclarecedores, principalmente dos que possuem menos conhecimentos em matéria de educação. Portanto, têm como responsabilidade atuar como orientadores ao mesmo tempo em que propõem soluções para as questões em educação, visando assim, qualificá-la (ELIAS SOBRINHO, 2008).

Tendo em vista a construção histórica desses órgãos mobilizadores que objetivam efetivar o modelo de gestão democrática, percebemos a necessidade de ampliar os estudos sobre como essa temática vem sendo vivenciada pelas diferentes localidades do país a partir da pesquisa desenvolvida, em parceria com a Rede MAPA, intitulada "Gestão democrática do ensino 
público: mapeamento das bases normativas e das condições político-institucionais dos Sistemas Municipais de Ensino", cujo objetivo era analisar o quadro normativo e as condições políticoinstitucionais relativos à gestão democrática do ensino público no âmbito dos Sistemas Municipais de Ensino do Estado do Maranhão de acordo com a atribuição que Ihes foi conferida pela atual Lei de Diretrizes e Bases da Educação (BRASIL, 2019, Art. 14), quanto à definição de normas de gestão democrática na educação básica, de acordo com suas peculiaridades. Ademais, surge da necessidade de considerar o atual cenário político marcado por uma crise federalista em que aumentam as tensões entre os entes federados, visto que vivenciamos a expansão de políticas centralizadoras e conservadoras que impactam na atuação dos municípios.

Desse modo, levando em conta as peculiaridades das unidades territoriais com foco no munícipio, este artigo tem como objetivo analisar como se expressa o princípio de gestão democrática nas legislações do ensino do município de São José de Ribamar/MA a fim de caracterizar e identificar os fundamentos legais que dão sustentação ao funcionamento do Conselho Municipal de Educação (CME), evidenciando a atuação desse órgão para a organização do ensino público e fortalecimento da democracia por meio do diálogo entre Estado e sociedade.

Para tanto, caracteriza-se a base legal relativa à normatização da gestão democrática do ensino público do CME investigado por meio da Lei Orgânica Municipal de 1990 (LOM) (SÃO JOSÉ DO RIBAMAR, 1990), Lei de criação do CME, Lei nº 342/1997 (SÃO JOSÉ DO RIBAMAR, 1997), e Lei de criação do Sistema Municipal de Ensino (SME), Lei n. 467/2002 (SÃO JOSÉ DO RIBAMAR, 2002); analisam-se os elementos constituintes do quadro normativo da gestão democrática do ensino no CME e identificam-se informações que caracterizam as dinâmicas de participação.

O presente trabalho de abordagem qualitativa estrutura-se em duas etapas. Primeiro realizou-se pesquisa bibliográfica com o objetivo de nos aproximar do tema investigado a partir da leitura de diferentes autores: Saviani (2017), Bordignon (2009), Martins (2001; 2002), dentre outros. A segunda etapa consistiu na pesquisa documental que compreendeu a análise das legislações do ensino, LOM e Leis de criação do CME e do SME de São José de Ribamar/MA, considerando, portanto, os documentos como fontes ricas e estáveis de dados, uma vez que subsistem por longos anos e pelo seu caráter legal tornam-se a mais importante fonte de dados (GIL, 2002). Cabe ressaltar que as etapas dessa investigação foram desenvolvidas durante as reuniões do Grupo de Pesquisa em Política e Gestão Educacional (GPPGE) da Universidade 
Federal do Maranhão (UFMA) com o apoio do CME de São José de Ribamar/MA, que disponibilizou as leis que compõem esse colegiado. A partir dessa legislação os dados foram coletados, organizados e analisados de acordo com a análise de conteúdo, como sugere Bardin (1977). Para tanto, no tratamento das leis elencamos unidades de contexto nos artigos e incisos referentes aos princípios, espaços e mecanismos de gestão democrática que, ao serem inseridos em quadros, nos levaram às inferências aqui apresentadas.

\section{Gestão democrática: conceitos e princípios}

A partir da Constituição Federal de 1988 surge um novo modelo de gestão pública da educação denominado gestão democrática, que segundo Bordignon e Gracindo (2000, p.147) “é um processo político-administrativo contextualizado, através do qual a prática social da educação é organizada, orientada e viabilizada". Essa forma de gestão foi complementada e regularizada pela Lei de Diretrizes e Bases da Educação (LDB/96) e reafirmada no Plano Nacional de Educação (PNE), Lei no 13.005/2014, instituindo-se, portanto, como instrumento de democratização dos sistemas educacionais do país. Importante ressaltar que pelo fato da LDB/96 não ter definido o significado, espaços e os mecanismos para a implementação do princípio de gestão democrática do ensino público, essa tarefa ficou a cargo dos sistemas de educação, nos termos do seu artigo 14 (BRASIL, 2019), que têm tido papel fundamental e ao mesmo tempo um grande desafio, o de garantir a atuação da sociedade e de fornecer mecanismos próprios para o exercício da participação popular na tomada de decisão sobre os assuntos educacionais.

Todavia, falar sobre gestão democrática de uma perspectiva de participação, autonomia, e direitos é desafiar o poder de um sistema que tenta regular a constituição social a partir de visões unilaterais, conservadoras, desiguais e intolerantes. Assim, discutir tal princípio é entrar em confronto com uma estrutura econômica neoliberal que vem sendo instituída ao longo da História e que está sustentada por relações de poder que buscam o tempo todo minimizar a ação do Estado na oferta de educação gratuita e de qualidade, que oprime e silencia a sociedade na tomada de decisão das políticas públicas em prol de interesses econômicos.

Acreditamos que ao problematizarmos como a gestão democrática da educação se institui no âmbito dos Conselhos Municipais de Educação, possivelmente podemos estar 
desvelando processos de controle, na perspectiva de ações centralizadoras, visto que estes colegiados estão inseridos em um estado essencialmente liberal que está a serviço do capital e atende aos interesses de uma minoria burguesa (SOUZA, 2010). Por outro lado, temos a possibilidade de revelar práticas mobilizadoras que pretendem alargar a participação social na esfera pública.

Uma análise que busque entender a consolidação dessa perspectiva democrática só será possível a partir da compreensão de que os sistemas de educação se enraízam profundamente no processo político da construção da democracia e consolidação do regime federativo que, por meio da descentralização, delega autonomia às unidades federadas e possibilita a criação de espaços de participação da sociedade nas decisões, acompanhamento e avaliação das políticas educacionais. Para tanto, a gestão democrática como princípio norteador da educação brasileira torna-se um modelo de gestão essencial por compactuar com os princípios democratizantes propostos na dinâmica político-administrativa do país.

Sobre a gestão democrática, Barbosa Filho $(2004$, p.3) afirma que esta é entendida como "a ação e o efeito de gerir a educação através da participação de todos os atores sociais que integram o universo educacional, objetivando atender às aspirações da sociedade". Considerando a finalidade desse tipo de gestão, os Conselhos de Educação devem então constituírem-se como órgãos de Estado que independem de governos para materializar suas ações e que, segundo Bordignon $(2009$, p.62) "formulam políticas educacionais para além da transitoriedade dos governos e suas vontades e preferências singulares". Na ótica democrática, os conselhos passam a representar uma estratégia privilegiada de democratização das ações do Estado, sendo a representatividade social uma de suas principais características.

Pode-se considerar que a constitucionalidade da gestão democrática como um princípio educacional é resultado dos processos de mobilizações por redemocratização do país que ocorreu no final da década de 1980 após um longo período ditatorial. Por isso, convém refletir acerca dos processos concomitantes a esse momento que nos remete a discussão da descentralização, autonomia e participação que se constituem como princípios que compõem a gestão democrática.

No âmbito administrativo da gestão política, o significado de autonomia estar associado à capacidade de autogoverno, à liberdade, à livre iniciativa da sociedade de dar leis a si própria, 
ao encontro de formas mais flexíveis de organização; além de redefinir formas de valorização do poder local e afirmação de singularidades (MARTINS, 2002). Para tanto, o processo de descentralização é tomado como medida que busca incentivar o pluralismo de ideias, o respeito às diferenças e a emergência de atores sociais. Tal medida, em suma, objetiva possibilitar maior participação e representação social; e visa à melhoria na qualidade dos serviços prestados por meio da possibilidade de gerenciar diretamente os recursos disponíveis aos âmbitos locais (MARTINS, 2001).

O conceito de autonomia está associado ao processo de descentralização pelo fato destes, por vezes, serem considerados como processos sequenciais. A descentralização é tida como reorganização político-administrativa que reparte entre os entes federados as competências e responsabilidades pela gestão educacional no âmbito de cada sistema de educação. Entende-se que a transferência de poder dos governos centrais para as estruturas político-administrativas locais, conferindo-lhes autoridade para decidir e formular suas políticas além de gerenciar e otimizar recursos próprios, é uma medida que viabiliza formas mais livres de organização dos sistemas educacionais e diminui a dependência do poder local em relação ao governo central; processo este que dá abertura à materialização do exercício de autonomia (MARTINS, 2001; NOVAES; FIALHO, 2010).

Somada aos princípios supracitados, a participação visa convocar a sociedade a agir em favor da melhoria da qualidade da educação, possibilitando a participação de diferentes segmentos desta nos processos de elaboração, implementação, avaliação e fiscalização das políticas educacionais. Nessa perspectiva, a educação assume o objetivo da emancipação humana que compreende "a superação da democracia formal instituindo a democracia real" (SAVIANI, 2017, p.656) por meio da conscientização dos cidadãos, que passam a participar de forma intencional e autônoma nas decisões dos rumos das políticas educacionais.

Portanto, participar na gestão de um sistema democrático simboliza partilha de poder em uma relação ativa, que não admite apatia e subordinação da sociedade. Para muito além, significa um exercício diário e gradual que tem como objetivo a transformação da realidade social em todos os seus âmbitos. É partindo dessa perspectiva e expectativa de transformação da realidade que analisamos o princípio de gestão democrática na legislação da educação de São José de Ribamar/MA, no tópico a seguir. 


\section{O munícipio de São José de Ribamar/MA}

Em nível de contextualização, cabem aqui algumas informações do município ao qual se refere o presente trabalho com o intuito de situá-lo territorialmente na conjuntura federativa brasileira.

O município de São José de Ribamar localiza-se na Mesorregião Norte do Maranhão, distancia-se a 30 km da capital São Luís, e compõe a região metropolitana desta, pois se situa no extremo leste da Ilha. Em um cenário litoral, seus principais atrativos são as paisagens naturais das belas praias que se juntam à beleza arquitetônica da Igreja da Matriz, cartão postal da cidade que atrai turistas de todas as regiões para um roteiro religioso. Somando-se ao turismo, as principais atividades econômicas são pesca, comércio, serviços e indústrias.

Desmembrado do município de São Luís desde 1952, São José de Ribamar possui população estimada em 179.028 pessoas e uma área de $180,233 \mathrm{~km}^{2}$, de acordo com dados do Instituto Brasileiro de Geografia e Estatísticas (IBGE, 2020). Ainda segundo os dados disponíveis no sítio do IBGE (2010), o Índice de desenvolvimento humano municipal (IDHM) era de 0,708, um pouco acima da média estadual que é de 0,639.

A respeito da organização da educação, o Censo Escolar de 2019 realizado pelo Instituto Nacional de Estudos e Pesquisas Educacionais Anísio Teixeira (INEP, 2019) revela que São José de Ribamar possui um total de 200 estabelecimentos escolares e a soma de 29.793 matrículas na Educação Básica distribuídas nas etapas de ensino e sob a responsabilidade das respectivas dependências administrativas, estadual, municipal e privada. Dados dessa mesma fonte dão indícios do processo de municipalização do Ensino Fundamental no município, pois revelam, por meio de números, que um pouco mais de cinquenta por cento das instituições $(50,5 \%)$ - no que se refere à dependência administrativa pública - estão exclusivamente sob a responsabilidade municipal, o Estado mantém 5,5\% e a instância federal 0,5\%, demonstrando dessa forma a descentralização da responsabilidade educacional local.

Considerando o exposto acima e perante a compreensão do direito social de acesso e permanência a uma educação de qualidade com vistas ao desenvolvimento de práticas de democratização do ensino (SARMENTO, 2005), é necessário observar que a organização do sistema municipal de educação abrange uma gama de mecanismos correlacionados que devem 
atuar em busca de transformações que objetivem atender aos anseios populares. Sendo assim, faremos, então, uma análise das legislações que sustentam a organização do ensino em São José de Ribamar, para a identificação dos princípios que orientam as políticas educacionais no município.

O munícipio de São José de Ribamar dispõe de LOM de 1990, Lei de criação do CME, no 342/97, e Lei de criação do SME, no 467/02. Sendo assim, analisaremos a seguir o princípio da gestão democrática nas respectivas leis.

\section{Análise do princípio de gestão democrática na Lei Orgânica Municipal}

O Brasil é uma República Federativa que confere aos Estados e Municípios autonomia para legislarem sobre assuntos locais. Isso implica dizer que não há supremacia da lei ordinária federal relativa à estadual e municipal, mas sempre deve ser lembrado que qualquer norma, por mais especial que seja, não poderá contrariar e em nenhuma hipótese poderá desrespeitar os dispositivos da Constituição Federal, que é a lei maior.

Partindo dessa premissa é importante ressaltar que a escolha pela Lei Orgânica, Lei de criação do SME e a Lei de criação do CME não se deu de forma aleatória. A primeira representa a lei maior no âmbito dos municípios, sendo, portanto um mecanismo importante para a institucionalização dos SMEs. A segunda e terceira por instituírem um dispositivo fundamental para criação do CME enquanto órgão normativo autônomo. Tal afirmação se sustenta na concepção de hierarquia das leis (LOM, SME e CME respectivamente), que no caso de São José de Ribamar/MA não corresponde à ordem cronológica. Assim, ao criar o SME depois do $\mathrm{CME}$, o referido município implicou na não formalização da sua autonomia enquanto a lei de criação daquele não havia sido institucionalizada, período este em que não poderia definir suas próprias normas nos termos da CF/88 e da LDB/96, ficando, portanto, subordinado às normas estaduais (BORDIGON, 2009).

Tanto o SME quanto o CME, quando bem conduzidos, podem representar o pilar de uma gestão democrática que envolve a participação da sociedade civil nas decisões políticas relacionadas à educação com função de normatizar, deliberar, assessorar e fiscalizar. Considerando o exposto, elaboramos o quadro abaixo para analisar os aspectos que concernem 
ao princípio da gestão democrática na LOM.

Quadro 1. Princípios da Gestão democrática do ensino na Lei Orgânica Municipal

\begin{tabular}{|c|l|}
\hline Lei & \multicolumn{1}{c|}{ Princípios } \\
\hline & $\begin{array}{l}\text { Art. 116 - O Município elaborará o estatuto do magistério, obedecendo às } \\
\text { finalidades legais e democraticamente com a participação do representante do } \\
\text { órgão de competência municipal, do representante legal de classe e de comissão } \\
\text { permanente de educação da Câmara Legislativa. }\end{array}$ \\
$\begin{array}{c}\text { Lei Orgânica de 5 } \\
\text { de abril de 1990 }\end{array}$ & $\begin{array}{l}\text { Art. 137 - Ficam criados os seguintes Conselhos: } \\
{[\ldots] I I-\text { Conselho Municipal de Educação; }} \\
\S 1 \text { 으- Os conselhos de que trata o artigo ficam incumbidos de desenvolver e } \\
\text { orientar sobre as políticas orientadas de cada um deles e se constituirão os } \\
\text { representantes dos poderes públicos e da sociedade civil, na forma da lei. }\end{array}$ \\
\hline
\end{tabular}

Fonte: Autores a partir da legislação municipal.

A partir dos dados do quadro 1 observa-se que a Lei Orgânica de São José de Ribamar não menciona o princípio de gestão democrática como fundamento da educação. No entanto, embora esse princípio esteja ausente, o legislador faz alusão ao processo de participação democrática de representantes da classe de professores na elaboração do estatuto do magistério e institui o Conselho Municipal de Educação, dentre outros Conselhos, como órgão representante dos poderes públicos e da sociedade civil ao incumbi-lo de desenvolver e orientar políticas.

Ao constituir o CME como órgão "representante de poderes públicos e da sociedade civil" o texto demonstra a tensão que envolve os órgãos de representação social, a qual se refere ao conflito de poder que os acompanha, visto que, historicamente, os interesses do poder público, em sua maioria, são contrários aos interesses da sociedade (SOUZA, 2010). Estes colegiados têm como função negociar e fazer mediação entre a sociedade e o governo, sem perder de vista que sua atuação é voltada para os interesses coletivos. Do contrário, podem se tornar órgãos de governo e, assim perder a autonomia, característica essencial dos Conselhos (BORDIGNON, 2009). Neste caso, a lei de criação do CME - a ser analisada posteriormente - deve deixar clara a natureza, funções e paridade desse órgão, a fim de alcançar a mediação entre governo e sociedade para se estruturar como órgão de Estado.

A falta de referência ao princípio de gestão democrática pela LOM, colabora para o não reconhecimento legal desse modelo de gestão na educação do município. A LDB 9.394/96, ao 
incumbir os sistemas de ensino de definirem as normas da gestão democrática no ensino público de acordo com as peculiaridades locais, no artigo 14 (BRASIL, 2019), buscou facilitar o processo de concretização dessa gestão por meio da autonomia dada aos municípios para a criação de normas que, ao serem orientadas pelos fundamentos democráticos, estabeleceriam mecanismos com condições de possibilitar a materialização.

Portanto, a não menção desse princípio pelo legislador "provoca um limite nas outras legislações que estão abaixo na pirâmide legal, tornando-as ineficazes" (SOARES, 2017, p.141) já que, considerando a hierarquia legal na esfera municipal a Lei Orgânica é superior às demais leis. Logo, em vez de contribuir e acelerar o processo de estabelecimento de instrumentos de materialização da gestão democrática acaba tornando esse modelo de gestão cada vez mais distante da realidade.

Embora a ausência da categoria de gestão democrática na lei maior do município dificulte o processo de ampliação dos mecanismos de democratização, deve-se considerar que no sistema de ensino essa lei vigora correlacionada a outras leis que visam organizar a educação e dar amplitude ao que nela está previsto. Portanto, sem querer incentivar a incoerência entre as leis visto que o ideal é que elas estejam alinhadas, não se pode também barrar ou desperdiçar as oportunidades de criação de estratégias que busquem inserir ferramentas que colaborem para democratizar o ensino nas normas que venham surgir posteriormente, ou seja, que possam ser promulgadas depois dela.

\section{Análise do princípio de gestão democrática na lei de criação do CME}

No plano político administrativo dos municípios no Brasil, no final da década de 1980 , o CME assume atribuições como órgão normativo que organiza e delibera sobre educação a fim de representar a sociedade civil no planejamento, avaliação e controle social da educação municipal. Não há obrigatoriedade na criação de Conselho de Educação pelos sistemas de ensino visto que esta ação é uma decisão do município. Portanto, pela quantidade de unidades territoriais municipais e pelas peculiaridades de cada uma delas, não é possível existir um modelo único de CME a ser seguido (BORDIGNON, 2009). Portanto, cada CME criado possui características próprias que expressam os fundamentos que orientam suas ações. Desse modo, 
apresentamos a seguir a análise da Lei nº 342 (SÃO JOSÉ DO RIBAMAR, 1997), que criou o CME de São José de Ribamar:

Quadro 2. Princípios da gestão democrática do ensino na Lei de criação do CME

\begin{tabular}{|c|c|}
\hline Lei & Princípios \\
\hline $\begin{array}{c}\text { Lei } 342 \text { de } 15 \text { de } \\
\text { dezembro de } \\
1997\end{array}$ & $\begin{array}{l}\text { Art. } 2 \text { - Respeitadas as competências exclusivas do Legislativo Municipal, } \\
\text { compete ao Conselho Municipal de Educação: } \\
\text { [...]II - Estabelecer as diretrizes a serem observadas na elaboração do Plano } \\
\text { Municipal de Educação; } \\
\text { [...]V - Propor critérios para a programação e para as execuções financeiras e } \\
\text { orçamentárias do Fundo Municipal de Educação; } \\
\text { VI - Acompanhar critérios para a programação e para as execuções financeiras } \\
\text { e orçamentárias do Fundo Municipal de Educação e fiscalizar a movimentação e } \\
\text { aplicação de recursos; } \\
\text { [...]XII - Zelar pela efetivação do sistema descentralizado e participativo de } \\
\text { Educação; } \\
\text { XIII - Convocar ordinariamente a cada } 2 \text { (dois) anos. Ou extraordinariamente, } \\
\text { por maioria absoluta de seus membros, a Conferência Municipal de Educação } \\
\text { que terá a atribuição de avaliar a situação da Educação e propor diretrizes para } \\
\text { o aperfeiçoamento do sistema; } \\
\text { XIV - Acompanhar e avaliar a gestão dos recursos, bem como, os ganhos sociais } \\
\text { e o desempenho dos programas e projetos aprovados; } \\
\text { Art. 3o - O CME terá a seguinte composição: } \\
\text { I- Do governo Municipal: } \\
\text { a) Divisão de Educação } \\
\text { b) Divisão de Cultura } \\
\text { c) Divisão de Finanças } \\
\text { d) Divisão de Administração } \\
\text { e) Secretaria de Saúde } \\
\text { II - Dos servidores da área: } \\
\text { a) Representante dos Professores da Escola de } 10 \text { grau } \\
\text { b) Representante dos Professores da Escola de } 20 \text { grau } \\
\text { III - Dos usuários: } \\
\text { a) Representante de aluno da Escola de } 10 \text { grau } \\
\text { b) Representante de aluno da Escola de } 20 \text { grau } \\
\text { Art. 9o - Todas as sessões do CME serão públicas e procedidas de ampla } \\
\text { divulgação. } \\
\text { Parágrafo Único - As resoluções do CME, bem como, os temas tratados em } \\
\text { plenário de diretoria e comissões, serão objeto de ampla e sistemática } \\
\text { divulgação. }\end{array}$ \\
\hline
\end{tabular}

Fonte: Autores a partir da Legislação municipal.

De acordo com o quadro acima, não se encontra de forma explícita o princípio de gestão democrática na lei de criação do CME. No entanto, o texto faz algumas menções às categorias 
ligadas aos princípios democráticos e, mesmo timidamente, podem colaborar e dar abertura para os processos de democratização da gestão da educação.

O conteúdo legal do CME de São José de Ribamar prevê a efetivação de um sistema de educação descentralizado e participativo. Isso deve refletir na composição dos conselheiros e na decisão de publicar as resoluções e temas tratados pelo $\mathrm{CME}$, bem como fazer pública as reuniões; e cita como instrumentos de participação o Plano Municipal de Educação (PME), a fiscalização dos recursos do Fundo Municipal de Educação (FME) e a Conferência Municipal de Educação. Entretanto, para que de fato esse tipo de sistema se efetive é necessário que as concepções previstas sejam materializadas por meio de ações coerentes, já que a falta de coerência compromete a prática democrática e, na legislação, pode deixar a entender que o objetivo é manter a democratização apenas no discurso.

No que tange à estrutura e organização do CME quanto à composição do quadro de conselheiros, a lei disciplina que estes serão nomeados pela prefeitura municipal mediante indicação do prefeito, como está escrito no artigo 4으 da Lei no 342/97 de criação do CME.

Art. 40 - Os membros efetivos e suplentes do CME serão nomeados pela Prefeitura Municipal mediante indicação.

Parágrafo Único - As representantes das categorias Municipais serão de livre escolha do Prefeito (SÃO JOSÉ DE RIBAMAR, 1997, s/p).

O legislador ainda acrescentou um parágrafo para reafirmar a "livre escolha do Prefeito" quanto aos representantes das categorias municipais, não definindo os critérios para indicação dos membros representantes das categorias dos servidores da área e dos usuários da educação. Sobre a composição e forma de escolha dos conselheiros, Bordignon (2009, p.70) alerta que:

Revelam a concepção e a natureza do conselho. Isto porque, em boa medida, determina em nome de quem e para quem opinam e decidem. Quando predominam representantes do Executivo, por vinculação a cargos ou livre nomeação, o conselho tende a expressar a voz do Governo.

Ainda para o autor supracitado a forma de escolha é um dado relevante para avaliar as condições de fidelidade no exercício da representação nos CMEs. Ou seja, quando a escolha se dá pela vontade dos representados, por meio de eleição direta, é de se esperar que o exercício 
da função seja pautado no princípio de gestão democrática. Mas, quando derivam da vontade singular, seja do prefeito, ou presidente do conselho ou outros, tenderão a fazer à vontade de onde deriva a indicação. Tal situação gera uma série de inibições e constrangimentos visto ser "antiético deliberar sobre matéria que seja submetida à sua homologação" (ROMÃO, 1992 apud RIBEIRO, 2004, p.79).

Apesar dessa forma de escolha, observa-se que o município conseguiu estabelecer em sua legislação o mecanismo de paridade, prevendo a participação de três segmentos sociais. Porém dos nove conselheiros, cinco representam o governo municipal, dois os servidores da área da educação e dois representantes dos alunos, não atendendo assim ao fundamento da pluralidade uma vez que o número de representantes do poder executivo é superior ao das outras categorias, sobre isso Bordignon (2009, p.70) alerta: "Quanto mais pluralidade das categorias de educadores e da comunidade estiver representada, mais os conselhos expressarão a voz e as aspirações da sociedade".

Constata-se a partir desses dados que o CME do município de São José de Ribamar vem assumindo característica de órgão de governo em vez de funcionar como órgão de Estado. Desse modo, a autonomia é comprometida por inferir em certa subordinação destes órgãos aos gestores de governos locais.

A disponibilização de algumas normas pela secretaria municipal de São José de Ribamar/MA, no sítio da prefeitura nos levou a ter acesso ao Decreto no 1321 de 2017 (SÃO JOSÉ DE RIBAMAR, 2017), que designa, para o biênio 2017/2019, a indicação dos membros titulares e suplentes do CME desse município. Fica decretado, portanto, a composição deste órgão por sete conselheiros, três representantes da Secretaria Municipal de Educação (SEMED) - incluindo a Secretária de Educação -, um representante dos diretores das unidades escolares municipais, um representante do sindicato dos professores, um representante do Conselho Municipal do Direito da Criança e do Adolescente e um representante da Câmara Municipal.

Nota-se que houve uma redução no número de conselheiros e que as categorias de representação do órgão foram mudadas em comparação ao que é previsto na lei de criação do CME, Lei no 342/97 (SÃO JOSÉ DE RIBAMAR, 1997). A aprovação deste Decreto com as referidas alterações permite a suposição de que as políticas municipais são engendradas, muitas vezes, pelos desejos singulares dos gestores, pois além da diminuição do número de conselheiros, 
inseriu-se ainda a secretária municipal de educação como membro deste conselho, o que pode gerar situações de constrangimento no que se refere à deliberação das ações.

Observa-se ainda que em relação a lei de criação do CME, Lei n. 342/97 (SÃO JOSÉ DE RIBAMAR, 1997), o Decreto não avança quanto à ampliação de espaços para representatividade social, pois, além do Conselho Municipal do Direito da Criança e do Adolescente, representantes de pais, dos alunos, do conselho tutelar e de outras entidades da sociedade civil organizada não foram mencionados.

A não participação de diferentes segmentos representantes da sociedade civil torna inviável a concretização do modelo de gestão democrática uma vez que este tipo de gestão pressupõe elaboração coletiva, eleição, caráter participativo, transparência, diálogo, justiça e competência que são intrínsecos ao exercício da cidadania democrática (CURY, 2002; PERONI, 2008). Desse modo, deve levar-se em consideração a diversidade de opiniões e multiplicidade de saberes para enriquecer a atuação dos Conselhos e garantir a participação dos diferentes grupos da sociedade civil que possui interesse em educação. Dublante (2011) assegura que:

[...] uma gestão democrática não pode acontecer sem o respeito à diversidade de opiniões dos sujeitos que contribuem para sua efetivação, nem sem o respeito às condições de cada localidade. [...] Entretanto, com decisões tomadas historicamente em gabinetes, sem a participação dos atores principais, essa 'definição de normas' fica apenas sob o olhar de quem está no comando da gestão (DUBLANTE, 2011, p.95).

As atribuições delegadas aos CMEs também revelam a natureza e o fundamento destes órgãos que, geralmente possuem funções normativas, deliberativas, consultivas e fiscalizadoras. No caso de São José de Ribamar, o CME possui função deliberativa explicitada em lei como única função deste órgão (SÃO JOSÉ DE RIBAMAR, 1997, Art. 1ํ). No entanto, atribui no decorrer do texto legal a função fiscalizadora para a gestão dos recursos financeiros e supervisão do funcionamento do sistema de ensino.

As funções normativas e consultivas são igualmente importantes e, também poderiam ser contempladas para que normas em favor da educação sejam pensadas por meio do exercício da autonomia que estes órgãos possuem, como também para a viabilização da participação comunitária por meio de consultas que indicariam os anseios populares e facilitariam a 
organização de ações voltadas para a democratização da gestão.

Além de todas as dificuldades supracitadas que impedem o exercício democrático de uma gestão participativa descentralizadora, outra situação encontrada no município de São José de Ribamar é a falta de espaço próprio para o funcionamento do CME. Pelo menos na legislação, não se estabelece um local fixo, onde os conselheiros possam se reunir e discutir em colegiado sobre as questões próprias da educação. Isso dificulta, segundo Ribeiro (2004), o desempenho das funções do órgão já que este demanda um espaço com materiais, documentos e pessoal devidamente organizado. Logo, a falta de condições para o exercício das atribuições impede a atuação competente dos Conselhos de Educação.

Com todas as questões apresentadas a partir das informações colhidas pela leitura das legislações do ensino de São José de Ribamar, percebe-se que é comum a ausência do princípio de gestão democrática do ensino público como fundamento de práticas de democratização, descentralização, participação, autonomia, diálogo e representatividade por eleição (GADOTTI; ROMÃO, 2004). Dessa forma, pressupõe-se a dificuldade do município em materializar ações voltadas para o coletivo por meio do conhecimento de suas necessidades via mediação entre sociedade e governo.

Essa dificuldade se coloca quando a estrutura legal da educação não estabelece princípios democráticos e nem estruturam mecanismos que facilitem a concretização destes sem que eles pairem apenas pela esfera discursiva. Nesse caso, os órgãos de representatividade social assumem características de governo ao manter ações burocráticas que denotam um conjunto de anseios e práticas de uma minoria, a qual não convoca a participação da sociedade civil por temer que seus interesses sejam abalados.

\section{Análise do princípio de gestão democrática na lei de criação do SME}

Os sistemas de educação se constituem a partir da intencionalidade de organização do ensino, de sistematização, com o objetivo de coordenar a educação no âmbito de cada esfera da federação. Portanto, é necessário que esse sistema se articule de forma que as políticas educacionais atendam aos interesses da sociedade brasileira. Sendo assim, configura-se como um conjunto coerente, arrumado, operante (SAVIANI, 2017). 
Desse modo, no percurso entre conhecimento das problemáticas a serem resolvidas na educação à superação destas, é necessária a organização dos elementos que compõem os sistemas para alcançar os objetivos almejados para a educação municipal. Logo, esta sistematização é pensada a partir de bases que nortearão as decisões e ações a serem planejadas e materializadas, as quais podem estar fundamentadas em princípios democráticos ou não.

Portanto, considerando o exposto, segue o quadro com análise de como se expressam os princípios da gestão democrática na Lei $n^{\circ}$. 467, de 2002 (SÃO JOSÉ DO RIBAMAR, 2002), que determina a criação do SME de São José de Ribamar:

Quadro 3. Princípios da Gestão democrática do ensino na Lei de criação do SME

\begin{tabular}{|c|c|}
\hline Lei & Princípios \\
\hline $\begin{array}{c}\text { Lei no } 467 \text { de } 30 \\
\text { de dezembro de } \\
2002 \text {. }\end{array}$ & $\begin{array}{l}\text { Art. } 2 \text { o - Compete ao Conselho Municipal de Educação, além de outras } \\
\text { atribuições previstas na Lei Municipal no } 342 \text {, de } 15 \text { de dezembro de 1997: } \\
\text { I - colaborar com o poder executivo na definição das políticas de educação } \\
\text { escolar no município, elaborando propostas para o Plano Municipal de Educação } \\
\text { e para as Leis Orçamentárias Anuais e Plurianuais; } \\
\text { II - assessorar a Secretaria Municipal de Educação na discussão do projeto } \\
\text { político pedagógico do sistema e das unidades escolares; } \\
\text { Art. 3o - A Secretaria Municipal de Educação é órgão próprio do sistema } \\
\text { municipal de ensino para planejar, coordenar, executar, supervisionar e avaliar } \\
\text { as atividades de ensino a cargo do Poder Público municipal no âmbito da } \\
\text { educação básica. } \\
\text { [...]§ 2o - As ações da Secretaria Municipal de Educação se pautarão pelos } \\
\text { princípios de gestão democrática, produtividade e racionalidade sistêmica e } \\
\text { autonomia das unidades escolares, priorizando a descentralização das decisões } \\
\text { pedagógicas, administrativas e financeiras. } \\
\text { Art. } 4 \text { - - As escolas da rede municipal, tanto as de educação infantil, como as de } \\
\text { ensino fundamental, médio e profissional, elaborarão periodicamente seu } \\
\text { projeto político pedagógico, dentro dos parâmetros da política educacional do } \\
\text { município e de progressivos graus de autonomia, e contarão com um regimento } \\
\text { escolar, dos quais farão cientes a Secretaria Municipal de Educação e o Conselho } \\
\text { Municipal de Educação; } \\
\text { Parágrafo Único - O projeto político pedagógico, o regimento escolar, além das } \\
\text { disposições legais sobre a educação escolar da União e do Município, constituir- } \\
\text { se-ão no referencial para a autorização de cursos e avaliação de qualidade, e } \\
\text { para a fiscalização das atividades dos estabelecimentos de ensino, de } \\
\text { competência do Conselho Municipal e da Secretaria Municipal de Educação. } \\
\text { Art. } 5 \text { o - As escolas, mantidas pela iniciativa privada, que oferecerem educação } \\
\text { infantil precisam ser credenciadas e ter seus cursos autorizados segundo }\end{array}$ \\
\hline
\end{tabular}

Periódico Horizontes - USF - Itatiba, SP - Brasil - e021017 


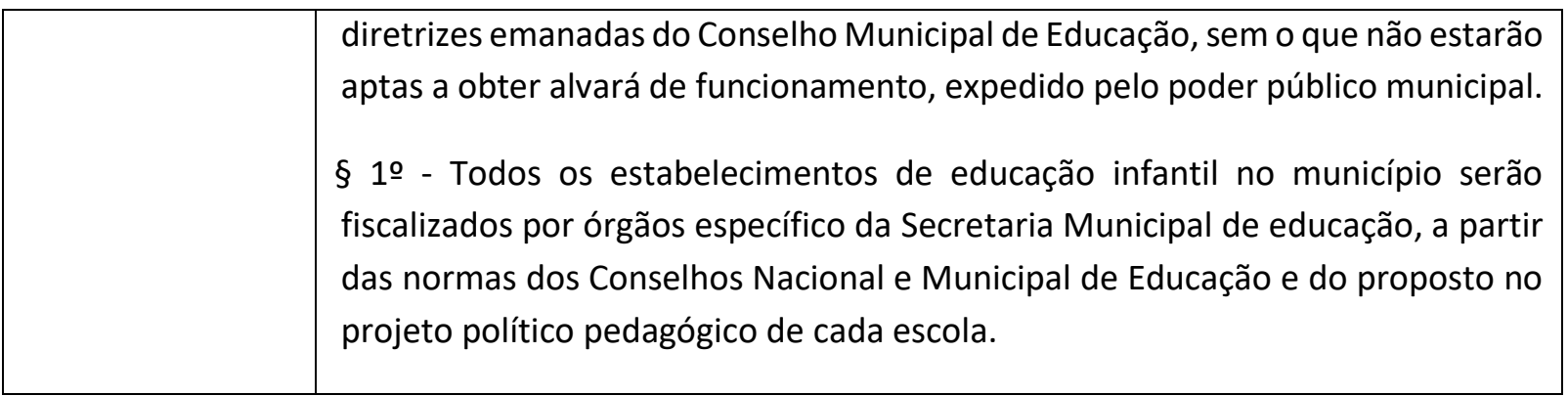

Fonte: Autores a partir da Legislação municipal.

Diferentemente da LOM, a lei de criação do SME, Lei no 467/02 avança e apresenta explicitamente a gestão democrática além de citar outros princípios, que compõem esse modelo de gestão, como: descentralização e autonomia. Espaços que ampliam o processo de democratização também são previstos, pois, além do $\mathrm{CME}$, a legislação menciona o Projeto Político Pedagógico (PPP) e o PME no artigo $2^{\circ}$, inciso I. Compete, portanto, aos responsáveis pela materialização desses espaços detalharem a forma como se dará a participação compreendida como "presença nos momentos de construção das políticas bem como também de fiscalização do cumprimento destas" (PIMENTA, 2019, p.116).

Cabe notar ainda que, nos termos dessa lei, o SME é composto pela SEMED, o CME, as escolas de educação básica e profissional mantidas pelo poder público municipal e as unidades escolares - creches e pré-escolas - mantidas e administradas pela iniciativa privada, tanto as de caráter lucrativo, como as comunitárias, confessionais e filantrópicas.

Entretanto, o parágrafo na lei que institui explicitamente o modelo de gestão democrática restringe as ações pautadas por este princípio apenas à SEMED. Mesmo que no texto, ainda nesse parágrafo (SÃO JOSÉ DO RIBAMAR, 2002, Art. 3ํ, §2ํ), delegue-se autonomia às unidades escolares por meio da descentralização das decisões pedagógicas, administrativas e financeiras, seria mais adequado e objetivo, se esse fundamento fosse eleito como princípio norteador de todo o SME, acompanhado não apenas das categorias de descentralização e autonomia, mas abrangendo também participação, eleição e outros mecanismos que colaboram para a concretização desse modelo de gestão, visto que os princípios de democratização "são as bases fundamentais da proposta de gestão democrática construída historicamente pelos educadores" (PERONI, 2008, p.201).

Uma das causas que poderia ter contribuído para que não tenha sido prevista a gestão 
democrática como fundamento de todo o sistema é o fato do CME compor o SME, pois seria uma forma de precaver incompatibilidade entre as leis, visto que a lei de criação do CME - criada anos antes da lei do SME - não menciona esse princípio como norteador das ações a serem desenvolvidas por esse órgão. No entanto, ainda que esta seja uma hipótese, não podemos considerá-la, uma vez que é possível encontrar outras incoerências entre as leis.

Logo, é por este motivo, dentre outros existentes, que nos sistemas de ensino deve-se atentar para a questão da hierarquia legal, observando quais leis possuem maior peso em relação às demais, ao mesmo tempo em que não se pode permitir que as legislações se tornem obsoletas, sendo indispensável, portanto, a atualização destas sempre que necessário para que de fato o sistema funcione como um conjunto coerente e arrumado sem perder de vista que a legislação é uma forma de organizar e de atender a objetivos e finalidades (CURY, 2000).

Nesse sentido, o SME enquanto articulador, responsável por conciliar o todo no âmbito administrativo (BORDIGNON, 2009), e como uma das principais heranças e ferramentas da autonomia delegada aos municípios, deve mobilizar o campo educacional para que as problemáticas no ensino sejam solucionadas por meio da abertura concreta à democratização.

Para tanto, devem-se estabelecer mecanismos que visem à participação da sociedade civil na tomada de decisão, no âmbito da gestão local, com o objetivo de melhorar a qualidade social da educação, visando à formação de sujeitos participantes, capazes de transformar a realidade mediante o pleno exercício da cidadania. Desse modo, a gestão democrática não será apenas uma menção pouco significativa nos textos legais.

\section{Considerações Finais}

O CME na função de órgão de representatividade social surgiu como consequência do processo de democratização iniciado legalmente com a CF/88 e reafirmado na LDB/96. Essas bases normativas dão abertura e autonomia aos municípios para organizarem seus sistemas de ensino em busca da ampliação dos espaços de participação comunitária a partir do fundamento no modelo de gestão democrática.

A gestão democrática inaugura um novo modo de administrar que, diferentemente de práticas centralizadoras e clientelistas, remete ao esforço para envolver o diálogo e a 
participação de diferentes categorias da sociedade civil em busca da resolução dos problemas e conflitos sociais tendo em vista a formação competente desses sujeitos para opinarem criticamente sobre a realidade, a fim de transformá-la pelo constante exercício da cidadania.

Portanto, pressupõe-se que os sujeitos serão convocados a ter parte na elaboração e fiscalização de políticas públicas a partir do entendimento de que a sociedade civil é capaz de elaborar normas para si, em vez de ser apenas espectadora à mercê de decisões tomadas de forma centralizada. Sendo assim, torna-se necessário a criação de espaços responsáveis pela mediação entre Estado e sociedade civil, para mobilizar os cidadãos a tomarem parte na democratização dos serviços destinados à comunidade. Para tanto, estes órgãos devem ser autônomos com vistas a representar e expressar os interesses coletivos que não devem se confundir com a vontade dos gestores. A autonomia é característica essencial que dar forma à democratização já que intenciona diminuir as práticas paternalistas e centralizadoras, historicamente disseminadas como bem social à população quando de fato expressam os anseios de uma minoria que concentra o poder (MARTINS, 2002).

Dessa forma, na atual política administrativa, o CME como órgão de controle social deve ser construído em bases democráticas por meio de seu caráter participativo, da eleição de seus membros com abertura para categorias de representantes da comunidade, relação paritária das categorias representadas para elaboração e tomada de decisões coletivas, além de transparência na gestão e fiscalização dos recursos financeiros. A natureza e atribuições do CME devem ser de conhecimento da comunidade para que esta busque participação e usufrua dos serviços prestados pelo órgão.

Apoiadas no contexto legal em que estes órgãos atuam e considerando as características e atribuições que devem assumir, por meio da análise das legislações do município de São José de Ribamar/MA, destacamos esses documentos como elementos constitutivos que expressam a política educacional em âmbito local e ajudam a compreender em quais bases se fundamentam a organização do ensino. Portanto, constatamos que o princípio de gestão democrática ainda que seja preconizado pelas legislações federais como fundamento do ensino, na esfera local, ainda se depara com dificuldades para ser materializado. O limite impõe-se por meio de leis que não reconhecem os princípios democráticos em seus conteúdos e, quando estes são mencionados, ora timidamente ou explicitamente, não são preconizados e elaborados meios que 
podem facilitar ou indicar ações voltadas para a construção da gestão democrática.

A menção do modelo de gestão democrática ou de princípios que remetem a este sem o acompanhamento de mecanismos para efetivá-lo não é suficiente para a construção de uma política educacional democrática. Portanto, a simples menção significa o reconhecimento da importância e necessidade da presença deste fundamento nos discursos, no entanto, na medida em que este se distancia da prática torna-se incoerente e pode deixar de possibilitar a participação coletiva na gestão da educação municipal. Logo, contribui para que o CME assuma características de governo e não de Estado, fazendo com que represente uma minoria e não o coletivo.

Sendo assim, a maneira de diminuir a discrepante distância entre o discurso e a prática é elaborando estratégias de atualização e alinhamento entre as legislações educacionais para evitar incompatibilidade legal; mencionar e tratar explicitamente os princípios democráticos; incluir nas normas mecanismos de materialização da gestão democrática com criação de espaços de participação autônomos com pluralidade de porta-vozes; mecanismos elaborados de forma objetiva e com possibilidade de concretização. Todavia, para possibilitar que essas estratégias sejam colocadas em prática é indispensável que os profissionais da educação assumam também a responsabilidade por reivindicar a democratização da gestão da educação pública por meio do conhecimento e cumprimento dos atos normativos.

Caso não se busquem meios de democratizar a gestão da educação, os órgãos que deveriam se constituir como instrumentos de participação e democracia podem contribuir com leis e práticas centralizadoras das políticas públicas, manter a burocracia dos órgãos públicos que, em nada, condiz com o modelo de gestão democrática que deve nortear os sistemas de ensino.

O CME exerce o poder de representatividade e, assim, é responsável pela democratização que viabiliza a participação direta, permite a participação da sociedade civil no âmbito dos governos. Se isso não ocorre, não é possível afirmar o caráter democrático desse órgão, mas apenas técnico. Este é o caso do CME de São José de Ribamar/MA que não apresenta a gestão democrática como princípio que norteará as políticas educacionais do município. E, embora este princípio seja previsto na lei do SME e conceitos relacionados a este como o de descentralização, autonomia e participação sejam mencionados, ainda é muito limitado quando se refere às estratégias que devem ser materializadas para que este modelo de gestão se efetive na prática. 
Contudo, não se podem perder as expectativas de formar uma sociedade democrática na qual o diálogo e a participação coletiva sejam elementos em constante construção. Para tanto, os cidadãos devem ser educados para a cidadania, para tomarem consciência da liberdade de expressão, da realidade e da necessidade de tomar parte em decisões por meio do engajamento nas esferas públicas da sociedade.

\section{Referências}

BARDIN, L. Análise de conteúdo. Trad. Luís A. Reto e Augusto Pinheiro. Lisboa, Portugal: Edições 70, 1977.

BARBOSA FILHO, J. I. Gestão democrática do ensino público: uma conquista em construção, 2004.

BORDIGNON, G. Gestão da educação no município: sistema, conselho e plano. São Paulo: Editora e Livraria Instituto Paulo Freire, 2009.

BORDIGNON, G.; GRACINDO, R. V. Gestão da educação: o município e a escola. In: FERREIRA, N. S. C.; AGUIAR, M. A. S. (orgs.). Gestão da educação: impasses, perspectivas e compromissos. São Paulo: Cortez, 2000, p.147-176.

BRASIL. [Constituição (1988)]. Constituição da República Federativa do Brasil, de 5 de outubro de 1988. Texto constitucional com as alterações adotadas pelas Emendas constitucionais n. ${ }^{\text {os }}$ 1/1992 a 90/2015, pelo Decreto legislativo no 186/2008 e pelas Emendas constitucionais de revisão nos1 a 6/1994. 48 ed. Brasília: Câmara dos Deputados, Edições Câmara, 2015.

BRASIL. Lei no 9.394, de 20 de dezembro de 1996. Lei de Diretrizes e Bases da Educação Nacional (LDB). 3. ed., Brasília: Senado Federal, Coordenação de Edições Técnicas, 2019.

BRASIL. Lei no 13.005, de 25 de junho de 2014, que aprova o Plano Nacional de Educação (PNE 2014-2024) e dá outras providências. Brasília: Câmara dos Deputados, Edições Câmara, 2014.

CURY, C. R. J. Os Conselhos de Educação e a gestão dos sistemas. In: FERREIRA, N. S. C.; AGUIAR, M. A. S. (orgs.). Gestão da educação: impasses, perspectivas e compromissos. São Paulo: Cortez, 2000, p.43-60.

CURY, C. R. J. Gestão democrática da educação: exigências e desafios. RBPAE, v.18, n.2, p.163174, jul./dez. 2002.

DUBLANTE, C. A. S. Gestão escolar: fundamentos e práticas no contexto das escolas públicas. São Luís, EDUFMA, 2011. 
ELIAS SOBRINHO, S. Conselho Estadual de Educação da Paraíba: protagonismo e atuação 1962/2002. João Pessoa, Editora Universitária UFPB, 2008.

GADOTTI, M.; ROMÃO, J. E. Autonomia da escola. 6. ed. São Paulo: Cortez, (Guia da escola cidadã); v. 1) 2004.

GIL, A. C. Como elaborar projetos de pesquisa. 4. ed. São Paulo: Atlas, 2002.

INSTITUTO BRASILEIRO DE GEOGRAFIA E ESTATÍSTICA - IBGE. Censo 2010. Brasília: IBGE, 2010. Disponível em: https://www.ibge.gov.br/cidades-e-estados/ma/sao-jose-de-ribamar.html?. Acesso em: 20 abr. 2020.

INSTITUTO BRASILEIRO DE GEOGRAFIA E ESTATÍ́sTICA - IBGE. Censo 2020. Brasília: IBGE, 2020. Disponível em: https://www.ibge.gov.br/cidades-e-estados/ma/sao-jose-de-ribamar.html?. Acesso em: 20 abr. 2020.

INSTITUTO NACIONAL DE ESTUDOS E PESQUISAS EDUCACIONAIS ANÍSIO TEIXEIRA - INEP. CenSO escolar 2019, Brasília: INEP, 2019. Disponível em: http://portal.inep.gov.br/censo-escolar. Acesso em: 20 abr. 2020.

MARTINS, A. M. A descentralização como eixo das reformas do ensino: uma discussão da literatura. Educação \& Sociedade, ano XXII, n.77, p.28-48, 2001.

MARTINS, A. M. Autonomia e educação: a trajetória de um conceito. Cadernos de Pesquisa, n.115, p.207-232, 2002.

NOVAES, I. L.; FIALHO, N. H. Descentralização educacional: características e perspectivas. RBPAE, v.26, n.3, p.585-602, 2010.

PERONI, V. M. V. Conselhos municipais em tempos de redefinição do conceito democracia. In: SOUZA, D. B. (org.). Conselhos municipais e controle social da educação: descentralização, participação e cidadania. São Paulo: Xamã, 2008, p.191-209.

PIMENTA, J. A. Gestão democrática da educação: análise da sua materialidade nos sistemas municipais de educação da mesorregião sul do Maranhão. 2019. 280f. Dissertação (Mestrado em Educação) - Programa de Pós-Graduação em Educação/CCSO. Universidade Federal do Maranhão, São Luís, 2019.

RIBEIRO, W. Municipalização: os Conselhos Municipais de Educação. Rio de Janeiro, DP\&A, 2004.

SÃO JOSÉ DE RIBAMAR. Lei Orgânica de 5 de abril de 1990. Dispõe sobre o município de São José de Ribamar. 1990. Disponível em:

http://arquivos.al.ma.leg.br:8080/ged/constituicoes_municipais/sao_jose_de_ribamar.pdf. Acesso em: 20 abr. 2020. 
SÃO JOSÉ DE RIBAMAR. Lei 342, de 15 de dezembro de 1997. Dispõe sobre a criação do Conselho Municipal de Educação. Câmara de vereadores, 1997, s/p.

SÃO JOSÉ DE RIBAMAR. Lei de 467 de 30 de dezembro de 2002. Dispõe sobre a criação do Sistema Municipal de Educação. Câmara de vereadores, 2002.

SÃO JOSÉ DE RIBAMAR. Decreto no. 1321. Designa os membros titulares e suplentes do Conselho Municipal de Educação para o biênio 2017/2019. 2017. Disponível em: http://www.saojosederibamar.ma.gov.br/legislacao. Acesso em: 20 abr. 2020.

SARMENTO, C. D. Criação dos sistemas municipais de ensino. Educação \& Sociedade, Campinas, v.26, n.93, p.1363-1390, set./dez. 2005.

SAVIANI, D. Sistema Nacional de Educação e Plano Nacional de Educação: significado, controvérsias e perspectivas. 2 ed. Campinas: Autores Associados, 2017.

SOARES, E. L. Gestão democrática: uma análise das bases normativas dos Sistemas Municipais de Educação do Maranhão. 2017. Dissertação (Mestrado em Educação) - Programa de Pósgraduação em Educação/CCSo, Universidade Federal do Maranhão, 2017.

SOUZA, R. M. Controle social e reprodução capitalista: polêmicas e estratégias contemporâneas. Temporalis, Brasília, ano 10, n.20, p.49-76, jul./dez. 2010.

Recebido em maio 2020.

Aprovado em janeiro 2021. 